\title{
The influence of comorbid personality disorders on recovery from depression
}

\author{
This article was published in the following Dove Press journal: \\ Neuropsychiatric Disease and Treatment \\ 16 March 2015 \\ Number of times this article has been viewed
}

\author{
Tinakon Wongpakaran \\ Nahathai Wongpakaran \\ Vudhichai Boonyanaruthee \\ Manee Pinyopornpanish \\ Suthi Intaprasert \\ Department of Psychiatry, Faculty \\ of Medicine, Chiang Mai University, \\ Chiang Mai, Thailand
}

Purpose: The impact of personality disorders on the treatment of and recovery from depression is still a controversial topic. The aim of this paper is to provide more information on what has led to this disagreement.

Materials and methods: Clinician-rated Hamilton Depression Rating Scale (HAMD) scores were assessed among 82 depressed outpatients who were receiving a routine treatment combination of antidepressant medication and psychosocial intervention. The participants were followed up over five visits at 3-month intervals: at the baseline, at 3, 6, 9 and 12 months. Personality disorders were assessed after the last visit in accordance with Diagnostic and Statistical Manual of Mental Disorders, Fourth Edition, Text Revision. These repeated measures were used to explore the impact of personality disorders on HAMD scores by using a linear mixed model.

Results: Among the four personality clusters that were used (A, B, C, and mixed), only those in cluster $\mathrm{B}$ and in the mixed cluster were found to take significantly longer than those without personality disorders, for reduction in HAMD scores over the course of treatment.

Conclusion: In this study, the impact of personality disorders on treatment outcomes varied with the way that the personality disorder variables were described and used as independent predictors. This is because the outcomes were influenced by the impact weight of each personality disorder, even within the same cluster.

Keywords: depressive disorder, mixed linear model, impact, multilevel analysis

\section{Introduction}

The influence of personality disorders (PDs) on depression has long been studied. Friborg et al revealed that over the last two decades, a number of studies have shown that PDs strongly influence depression, ${ }^{1}$ and in this review cluster C PDs were found to dominate in unipolar depression. However, the impact of different types of PDs on depression has varied from study to study. ${ }^{2-6}$ Most clinicians have pointed to a significant delaying effect of PDs on treatment outcomes, such as on remission among mood disorders and on acceleration of relapse times for those mood disorders. ${ }^{3,5,7-13}$ However, the researchers of some studies have found contrasting results and claimed that PDs may not necessarily have a negative effect on treatment outcomes. ${ }^{14-16}$

De Bolle et al suggested that these disagreements may have arisen from the specific statistical approach adopted to analyze the data across the different studies. ${ }^{17}$ They added that prior studies have adopted a single-level variable approach in the statistical data analysis and have shown that a single-level regression shows significantly worse treatment outcomes for patients with comorbid PDs than for patients with no PDs. They pointed out that this occurs because of heteroscedasticity. (Error term variances vary across observations and thereby violate the linear regression assumption and lead to incorrect results; the result of this makes PD look like a predictor.) When
Correspondence: Tinakon Wongpakaran Department of Psychiatry, Faculty of Medicine, Chiang Mai University, I 10 Intawarorot Road, Tambon Sriphum, Amphur Muang, Chiang Mai 50200,

Thailand

Tel +6653945422

Fax +66 53945426

Email tinakon.w@cmu.ac.th 
data were controlled for heteroscedasticity, De Bolle et al found PDs had no effect on treatment outcomes. They also found that personality pathology did not have a moderating effect on the severity of initial depressive symptoms, and so concluded that no evidence exists to suggest that the presence of personality pathology is significantly powerful in psychotherapeutic treatment conditions. ${ }^{17}$ In the study by De Bolle et al two assessments for depression were carried out, and only dichotomous variables were used to test for the effectiveness of PD as a predictor. ${ }^{17}$

However, Moradveisi et al ran a study based on similar multilevel model analysis, but they used a linear mixed model and gained different results; the researchers found that comorbid PD pathology, especially for patients from cluster $\mathrm{C}$, is associated with more severe depression but not with a lack of response to treatment. Comorbid PD was also a predictor for an increased chance of dropout. ${ }^{18}$

By using a similar multilevel model approach, we sought to establish the effect of PDs in a practical setting and based our study on a naturalistic, longitudinal, and observational study of depression treatment outcomes. We wanted to demonstrate the effect of PDs on depression not only at the end of a course of treatment, but also in terms of its moderating effect over the course of time; in this case, we studied a 12-month treatment period on the basis of five visits at 3-month intervals. To do that, we tested by using multilevel analysis for three reasons: 1) The study group could be regarded as representing a sample from the real population, and we wished to draw conclusions that relate to depressed outpatients; 2) Unexplained variability in the group-level variable (patient level) has previously been shown; and 3) For a small-sized group, using a random coefficient model is more appropriate than using a covariance model. ${ }^{19}$

\section{Materials and methods}

\section{Participants}

This study was an extension of the Thai Study of Affective Disorders (THAISAD), which is a 1-year follow-up study of depression treatment outcomes. ${ }^{20}$ The participants were diagnosed as having depressive disorders according to the Diagnostic and Statistical Manual of Mental Disorders (DSM), Fourth Edition, Text Revision (DSM-IV-TR) by using the Mini International Neuropsychiatric Inventory (MINI). ${ }^{21,22}$ This study was carried out in Chiang Mai over a 12-month follow-up period, during which data were gathered on five visits at 3-month intervals. Out of the 140 patients that were recruited, 85 participated and produced complete data for analysis. A previous study endorsed the stability of PD regardless of the condition (nonremitted or remitted) of the patients; ${ }^{23}$ therefore, all patients here were interviewed at the end of the THAISAD project.

As part of the outpatient services provided, each patient was seen by more than one therapist over a 12-month course of treatment. For this study, seven psychiatrists and 14 psychiatry residents were allocated to the 85 participants. In total, $68 \%$ of the patients received a combination of a selective serotonin reuptake inhibitor (SSRI) as an antidepressant and counseling or supportive therapy after the medication had been reviewed; the therapy for each participant was assigned on the basis the of the patient's symptoms and the therapists' judgments. A few patients received additional therapy, such as psychodynamic therapy, cognitive behavioral therapy, or group therapy.

\section{Measurement}

The Hamilton Rating Scale for Depression-17 (HAMD) was used to assess the severity of patient depression. The Thai version of the HAMD used in the study demonstrated good reliability and validity. ${ }^{24}$ All the participants were rated by using the HAMD for each of the five visits that took place over the 12-month course of treatment (one visit at the baseline and then one visit every 3 months).

The Thai version of the Structured Clinical Interview for $D S M-I V$ Axis II Personality Disorders instrument was used to measure for $\mathrm{PDs}^{25}$ and has shown good reliability. ${ }^{26}$ The interviews were carried out after the final visit (at 12 months), and these were undertaken by three psychiatrists and a social worker, all four of whom were fully trained and experienced clinicians who had been working with adult psychiatric patients for more than 20 years. The raters were blindfolded when presented with the results of the treatment outcomes and any HAMD scores. Before being interviewed, each participant completed a personality screening questionnaire and then a follow-up with an interview if a particular trait produced at least two positive ("yes") responses from the self-report questionnaire. PDs, which are regarded as independent variables, were labeled according to the cluster in which an individual's PD fell: cluster A, B, or C. The mixed cluster was adopted when an individual was diagnosed with two or more PDs across the different clusters.

The study's procedures were approved by the Institutional Review Board of Chiang Mai University and followed the Declaration of Helsinki and the Good Clinical Practice Guidelines.

\section{Statistical analyses}

As mentioned above, as part of the outpatient service, each patient was seen by more than one therapist (or psychiatrist) 
and provided with counseling or supportive therapy according to the patient's needs. For the study, the amount of time the therapists spent with each patient varied. As a result, the collected data were analyzed by using a two-level analysis; the duration of the visits was treated as level 1 and was nested within each patient (level 2). ${ }^{27}$

Because we intended to focus on the whole model (both fixed and random effects), the maximum likelihood method was used. ${ }^{28}$ To select the best model, -2 log-likelihood and the Akaike Information Criterion (AIC) were used. Generally, smaller statistical values reflected a better model fit to the data. The HAMD score was the outcome (dependent) variable, whereas time and PD clusters were independent variables (predictors). A low score for the HAMD variable indicated that the patient had responded better clinically after treatment than before treatment. Since the data were nonnormal, prior to the analysis of the data, transformation was conducted. As suggested by Hox, to avoid multicollinearity due to equally spaced time intervals, the polynomials were transformed to become orthogonal or uncorrelated before the analysis took place ${ }^{29}$ and were centered in order to make their means equate to $0 .{ }^{19}$ Three cases were found to be outliers and hence were removed from the analysis. This left 82 cases to be used as part of the final analysis.

The illustration shown in Figure 1 suggests that both linear and quadratic time (time square) effects may be necessary to define changes in participant HAMD scores over time; therefore, in this study, time was treated as both a fixed and random effect, then by time-squared, and after that by time-cubed. However, since adding time-cubed did not significantly improve the model's fit over the previous version, the cubed parameters were not retained in the subsequent models. An unstructured covariance structure for the repeated measures yielded the best fit to the data. In the end, time, time-squared, PD clusters, PD interactions, and the predictors were included as fixed effects in the model, and time was tested for both random intercept and slope effects. To provide more detailed results, two approaches were used: one with a dichotomous PD variable (PD versus no $\mathrm{PD}$ ) and one with specific categorical PD variables (clusters A, B, C, and mixed).

Analyses were performed by using the mixed model procedure with SPSS 22.0 statistical software (IBM SPSS Statistics for Windows, version 22.0; IBM Corporation, Armonk, NY, USA).

\section{Results}

Preliminary analyses demonstrated that the HAMD scores were not related to any of these patient traits: sex

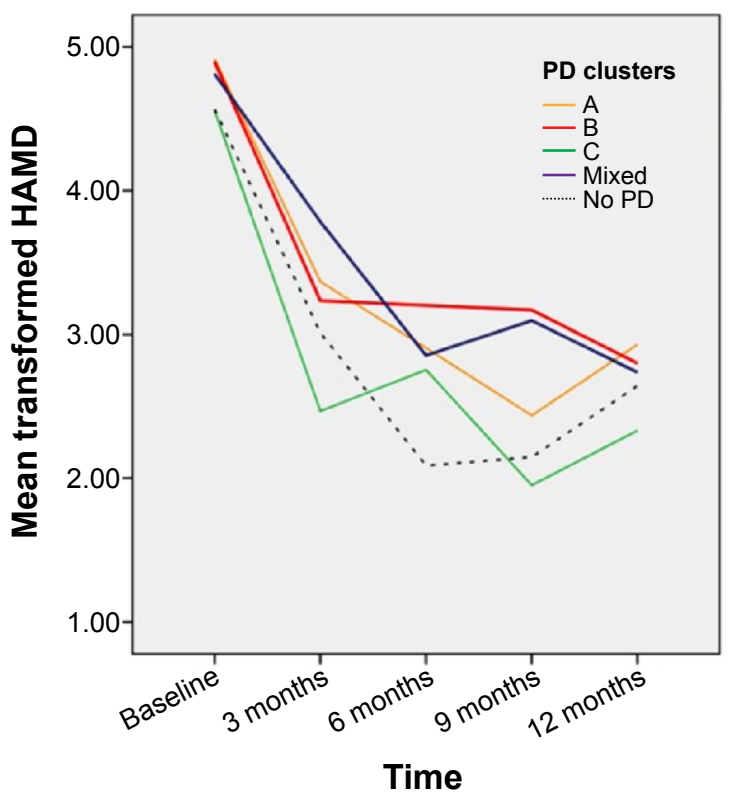

Figure I HAMD score over time by PD cluster $(\mathrm{N}=82)$.

Abbreviations: HAMD, Hamilton Rating Scale for Depression- 17; PD, personality disorder; $\mathrm{N}$, number of subjects in study.

$(\mathrm{F}[1,15.44]=0.442, P>0.05)$, age $(\mathrm{F}[1,13.84]=2.94$, $P>0.05)$, education $(\mathrm{F}[1,15.19]=2.47, P>0.05)$, or marital status $(\mathrm{F}[1,15.58]=1.11, P>0.05)$. Therefore, these variables were not controlled for in the further analyses.

Table 1 shows the sociodemographic characteristics of the participants and the PD distribution among them. The participants' mean age was 46 years, and $80 \%$ of the respondents were female. Most of the patients had been educated at least to high school level. In terms of marital status, $35(41.2 \%)$ were cohabitating. Most of the respondents were employed (76.5\%). Most of the participants had been prescribed an SSRI as an antidepressant. In terms of the severity of depression, the mean HAMD scores of all participants at the baseline was 22.74, then decreased over the course of treatment. Most of the participants (78\%) had one of each PD and hence were in the mixed cluster. In terms of specific PDs, borderline PD was prominent among cluster B, while obsessive-compulsive PD was prominent in cluster $\mathrm{C}$. Depressive and passive-aggressive PDs were found to be prevalent, but both were categorized in the mixed cluster since none of participants had either of them as a single PD.

In terms of the mixed cluster (number of participant $[\mathrm{N}]=25)$, the distribution of PDs was as follows: ten (40.0\%) had avoidant PD; 21 (84.0\%) had obsessive-compulsive PD; 19 (76.0\%) had paranoid PD; 23 (92.0\%) had schizotypal PD; 13 (52.0\%) had schizoid PD; two (8.0\%) had histrionic PD; four (16.0\%) had narcissistic PD; three (12.0\%) had antisocial PD; seven (28.8\%) had passive-aggressive PD; and nine $(36.0 \%)$ had depressive PD. 
Table I Sociodemographic characteristics of the study patients

\begin{tabular}{|c|c|c|}
\hline Variable & $\begin{array}{l}\text { Mean } \pm \text { SD } \\
(\min -\max )\end{array}$ & n (\%) \\
\hline Age (years) & $46.3 \pm 14.4(19-81)$ & $\mathrm{N} / \mathrm{A}$ \\
\hline \multicolumn{3}{|l|}{ Sex } \\
\hline Male & $\mathrm{N} / \mathrm{A}$ & $17(20.0)$ \\
\hline Female & $N / A$ & $68(80.0)$ \\
\hline \multicolumn{3}{|l|}{ Education } \\
\hline Elementary to junior high & N/A & $31(36.5)$ \\
\hline High school & $\mathrm{N} / \mathrm{A}$ & $\mid 8(2 \mid .2)$ \\
\hline Bachelor's degree or higher & $N / A$ & $36(42.4)$ \\
\hline \multicolumn{3}{|l|}{ Marital status } \\
\hline Single & $\mathrm{N} / \mathrm{A}$ & $27(31.8)$ \\
\hline Cohabitating or married & N/A & $35(4 \mid .2)$ \\
\hline $\begin{array}{l}\text { Living alone (widowed/ } \\
\text { divorced/separated) }\end{array}$ & $N / A$ & $23(27.1)$ \\
\hline \multicolumn{3}{|l|}{ Employment } \\
\hline Yes & $N / A$ & $65(76.5)$ \\
\hline No & N/A & $20(23.5)$ \\
\hline \multicolumn{3}{|l|}{ Type of antidepressant } \\
\hline SSRI & N/A & $56(68.3)$ \\
\hline Non-SSRI & $N / A$ & $26(31.7)$ \\
\hline \multicolumn{3}{|l|}{ HAMD scores } \\
\hline At 0 month (baseline) & $22.74 \pm 6.23(1 \mathrm{I}-38)$ & \\
\hline At 3 months & $12.75 \pm 10.32(0-38)$ & \\
\hline At 6 months & $9.59 \pm 8.30(0-29)$ & \\
\hline At 9 months & $9.06 \pm 7.99(0-31)$ & \\
\hline At 12 months & $8.73 \pm 6.27(0-25)$ & \\
\hline \multicolumn{3}{|l|}{ Personality disorders variables } \\
\hline No personality disorder & N/A & $20(23.5)$ \\
\hline Cluster A & $N / A$ & $10(11.8)$ \\
\hline Cluster B & $N / A$ & $18(21.2)$ \\
\hline Cluster C & $N / A$ & $12(14.1)$ \\
\hline $\begin{array}{l}\text { Mixed cluster ( } \geq 2 \text { cross- } \\
\text { cluster PDs) }\end{array}$ & $N / A$ & $25(29.4)$ \\
\hline \multicolumn{3}{|l|}{ Specific single PD } \\
\hline Avoidant & $N / A$ & $2(2.4)$ \\
\hline Dependent & $N / A$ & $\mathrm{I}(\mathrm{I} .2)$ \\
\hline Obsessive-compulsive & $N / A$ & $9(10.6)$ \\
\hline Paranoid & $N / A$ & $4(4.7)$ \\
\hline Schizotypal & $N / A$ & $4(4.7)$ \\
\hline Schizoid & $N / A$ & $2(2.4)$ \\
\hline Histrionic & $N / A$ & $0(0)$ \\
\hline Narcissistic & $N / A$ & $0(0)$ \\
\hline Borderline & $N / A$ & $17(20.0)$ \\
\hline Antisocial & N/A & $\mathrm{I}(\mathrm{I} .2)$ \\
\hline Passive-aggressive & $\mathrm{N} / \mathrm{A}$ & $0(0)$ \\
\hline Depressive & $N / A$ & $0(0)$ \\
\hline
\end{tabular}

Abbreviations: SD, standard deviation; min, minimum; max, maximum; n, number of subjects; N/A, not applicable; SSRI, selective serotonin reuptake inhibitor; PD, personality disorder; HAMD, Hamilton Rating Scale for Depression- 17.

Figure 1 shows that the trajectories were nonlinear; the reduction in HAMD scores was initially rapid and then slowed down. Table 2 shows clearly that some participants had consistently higher HAMD scores than others, so a random intercept appeared to be warranted. The estimated random-intercept standard deviation was 0.346 (model 1). We then included a random slope $\left(\sigma_{\text {time: patient }}^{2}\right)$ to allow participants to vary in their overall rate of change. Both the random intercept and slope were found to be significant in subsequent models. For models 3 and 4, when PD and PD*time interactions were included, the effect of PDs in model 3 (coefficient $=-0.343$, standard error $=0.174, P=0.053$ ) was almost significant. However, it did become significant in model 4 when interactions between PDs and time were added to the model. Model 4 yielded the lowest -2 maximum loglikelihood value, but it did not differ significantly from model 3.

Table 3 shows that both time $(b=-0.0496, P<0.001)$ and quadratic time $(b=0.359, P<0.001)$ were significant predictors of the HAMD score. HAMD scores were more significantly predicted by cluster $\mathrm{B}(b=0.783, P=0.011)$ and by the mixed cluster ( $b=0.673, P=0.02)$ than by the no-PD group. The interaction between the PD groups, except for the mixed cluster, and time showed no significant difference from the interaction between time and the no-PD group. The interaction between the mixed cluster and quadratic time showed a more negative and more significant impact on HAMD scores than did the interaction between quadratic time and the no-PD group ( $b=-0.198, P=0.033)$. Thus, the difference between the mixed cluster group and the no-PD group was smaller with more time squares.

\section{Discussion}

This study investigated the effects of PD and specific PDs on patients' recovery from depression, and the results show that PD did have an effect over the course of treatment. The results found here also support the findings of the study by Strandholm et al that was conducted in a naturalistic treatment setting and assessed 1-year treatment outcomes among depressed adolescents, either with or without comorbid Axis II disorders, in an outpatient setting. The researchers found that depression treatment outcomes were poorer for those in the PD group than for those in the no-PD group. ${ }^{30}$

In terms of the impact of specific PDs on treatment outcomes, this study's findings were similar to those revealed previously by Moradveisi et al. ${ }^{18}$ As found in other studies, cluster B played a role in the rate of recovery from depression, ${ }^{23,31,32}$ and in this study, cluster B was dominated by borderline PDs, with borderline PDs found to be related to remission. ${ }^{33-35}$ Other recent studies have also shown that borderline PD does not only delay the onset of remission but has a strong and statistically significant reciprocal effect and accelerates the time to relapse. ${ }^{7,36}$ Regarding the mixed cluster, our findings also supported the meta-analytic 
Table 2 Multilevel models for PD and time on HAMD scores $(\mathrm{N}=82)$

\begin{tabular}{|c|c|c|c|c|c|c|c|c|}
\hline \multirow{2}{*}{$\begin{array}{l}\text { Model } \\
\text { description }\end{array}$} & \multicolumn{2}{|l|}{$\begin{array}{l}\text { Random } \\
\text { intercept }\end{array}$} & \multicolumn{2}{|c|}{$\begin{array}{l}\text { Random intercept } \\
\text { and random slope }\end{array}$} & \multicolumn{2}{|c|}{$\begin{array}{l}\text { Including } \\
\text { PD variable }\end{array}$} & \multicolumn{2}{|c|}{$\begin{array}{l}\text { Including PD } \\
\text { variable and } \\
\text { PD interaction }\end{array}$} \\
\hline & Estimate & SE & Estimate & SE & Estimate & SE & Estimate & SE \\
\hline \multicolumn{9}{|l|}{ Fixed part } \\
\hline Intercept & 3.288 & $0.089^{b}$ & 3.291 & $0.102^{\mathrm{b}}$ & 3.018 & $0.170^{\mathrm{b}}$ & 2.814 & $0.230^{\mathrm{b}}$ \\
\hline Time & $-0.47 \mid$ & $0.038^{\mathrm{b}}$ & -0.478 & 0.432 & -0.481 & $0.043^{b}$ & -0.496 & $0.105^{b}$ \\
\hline Time square & 0.247 & $0.034^{b}$ & 0.243 & 0.031 & 0.244 & $0.03 I^{b}$ & 0.356 & $0.075^{b}$ \\
\hline PD & & & & & -0.343 & 0.174 & 0.590 & $0.255^{a}$ \\
\hline PD * Time & & & & & & & 0.020 & 0.115 \\
\hline PD $*$ Time square & & & & & & & -0.137 & 0.082 \\
\hline \multicolumn{9}{|l|}{ Random part } \\
\hline$\sigma_{\text {intercept: patient }}^{2}$ & 0.346 & $0.087^{b}$ & 0.546 & $0.132^{\mathrm{b}}$ & 0.513 & $0.124^{b}$ & 0.518 & $0.124^{b}$ \\
\hline$\sigma_{\text {intercept, time: patient }}$ & & & 0.115 & $0.046^{\mathrm{a}}$ & 0.113 & $0.044^{\mathrm{a}}$ & 0.113 & $0.043^{\mathrm{a}}$ \\
\hline$\sigma_{\text {time: patient }}^{2}$ & & & 0.053 & $0.025^{\mathrm{a}}$ & 0.053 & $0.024^{\mathrm{a}}$ & 0.054 & $0.024^{a}$ \\
\hline \multicolumn{9}{|c|}{ Model information criteria } \\
\hline-2 log-likelihood & 883.088 & & 869.158 & & 865.397 & & 861.890 & \\
\hline AIC & 901.088 & & 891.158 & & 889.397 & & 889.890 & \\
\hline
\end{tabular}

Notes: aStatistically significant at $P<0.05$. 'Statistically significant at $P<0.00$ I. The symbol* denotes interaction between two variables. The symbol $\sigma$ denotes covariance; $\sigma^{2}$ denotes variance.

Abbreviations: PD, personality disorder; HAMD, Hamilton Rating Scale for Depression-I7; N, number of subjects in study; SE, standard error; AIC, Akaike Information Criteria.

studies conducted by Friborg et al which found that a mixed personality cluster has more of an effect than any particular PD cluster. ${ }^{1}$ In fact, a mixed cluster can be viewed more as an accumulated PD (based on the severity of the PD) rather than as any specific type of PD. In this study, therefore, the more severe the $\mathrm{PD}$ that a participant possessed, the less his or her HAMD score improved over a given period of treatment (such as between month 3 and month 9). However, it may be speculated that those participants in mixed clusters exhibited a delayed response because their therapists, prompted by the severity of the patients' symptoms during the first few visits, provided more interventions; hence, the symptoms of the patients subsequently improved, and their HAMD scores were similar to those with no PD by month 12 . In terms of the

Table 3 Predictors of HAMD scores by personality cluster plus interactions over time

\begin{tabular}{|c|c|c|c|c|c|c|c|}
\hline \multirow[t]{2}{*}{ Parameters } & \multirow[t]{2}{*}{ Estimate } & \multirow[t]{2}{*}{ SE } & \multirow[t]{2}{*}{$d f$} & \multirow[t]{2}{*}{ t-value } & \multirow[t]{2}{*}{$P$-value } & \multicolumn{2}{|c|}{$95 \%$ confidence interval } \\
\hline & & & & & & Lower bound & Upper bound \\
\hline Intercept & $2.84 I$ & 0.225 & 86.779 & 12.624 & 0.000 & 2.394 & 3.289 \\
\hline Cluster A & 0.431 & 0.360 & 76.968 & $\mathrm{I} .197$ & 0.235 & -0.286 & 1.148 \\
\hline Cluster B & 0.793 & 0.304 & 81.440 & 2.606 & 0.011 & 0.188 & 1.399 \\
\hline Cluster C & 0.074 & 0.333 & 78.972 & 0.221 & 0.826 & -0.590 & 0.737 \\
\hline Mixed cluster & 0.673 & 0.284 & 81.562 & 2.368 & 0.020 & 0.108 & 1.238 \\
\hline No PD & $0^{\mathrm{a}}$ & 0.000 & - & - & - & - & - \\
\hline Time & -0.496 & 0.104 & 52.941 & -4.786 & 0.000 & -0.704 & -0.288 \\
\hline Time square & 0.359 & 0.075 & I 18.338 & 4.809 & 0.000 & 0.211 & 0.507 \\
\hline Cluster A * time & 0.003 & 0.152 & 49.556 & 0.020 & 0.984 & -0.302 & 0.308 \\
\hline Cluster B* time & 0.074 & 0.138 & 53.178 & 0.533 & 0.596 & -0.203 & 0.351 \\
\hline Cluster $C *$ time & -0.061 & 0.152 & 55.562 & -0.401 & 0.690 & -0.366 & 0.244 \\
\hline Mixed cluster $*$ time & 0.029 & 0.128 & 52.577 & 0.224 & 0.824 & -0.229 & 0.286 \\
\hline No PD * time & $0^{\mathrm{a}}$ & 0.000 & - & - & - & - & - \\
\hline Cluster $\mathrm{A} *$ time square & -0.057 & 0.112 & 110.740 & -0.507 & 0.613 & -0.278 & 0.165 \\
\hline Cluster B $*$ time square & -0.142 & 0.100 & 111.332 & -1.423 & 0.158 & -0.340 & 0.056 \\
\hline Cluster $C *$ time square & -0.091 & 0.107 & 109.324 & -0.852 & 0.396 & -0.303 & 0.121 \\
\hline Mixed cluster $*$ time square & -0.198 & 0.091 & I I 2.446 & -2.165 & 0.033 & -0.379 & -0.017 \\
\hline No PD * time square & $0^{\mathrm{a}}$ & 0.000 & - & - & - & - & - \\
\hline
\end{tabular}

Notes: a This parameter is set to zero because it is redundant. Interaction between two variables is denoted by the symbol*.

Abbreviations: SE, standard error; $d f$, degrees of freedom; PD, personality disorder; HAMD, Hamilton Rating Scale for Depression- 17. 
psychosocial interventions used with some of the participants (those interventions which might have impacted outcomes for particular PDs), these are not explicitly described in this paper. However, it is assumed that the impacts of these would have been minimal; the outpatient service that is used here is overworked and under-resourced in terms of the number of psychosocial treatment resources available. As a result, the treatments routinely rely on the provision of antidepressant medication primarily, with the provision of specific psychotherapy given only upon request. For example, during the study, only a few patients received a formal offer of psychotherapy provided in conjunction with medication. Therefore, any psychosocial treatment variable, despite its importance, was omitted from the study's analysis.

As revealed by Mulder the influence of PDs on treatment outcomes may have turned out to be different due to the design of the study ${ }^{16}$ and in particular how the investigators viewed personality and how the PD variable was used. In this regard, there are a few points on which we would like to comment.

First, could the effect of a PD be examined over more than two time points? Several measurements would allow patterns of change to be viewed over time. The important thing is to differentiate between the nonexistence and existence of PD effects, as well as how they diminish over the course of treatment. This difference might become apparent after several measurements have been taken. In addition, PD has an interaction effect not only with depression itself (Axis I disorder) as mentioned earlier, but also with time. Therefore, a study designed to capture the effect of PD by measuring at only two time points (ie, pre- and posttreatment) may make it difficult to conclude whether PDs affect depression outcomes or not.

Second, the way PD is used as an independent variable or a predictor is also important. Our results show that when using a dichotomous PD variable, the interaction effect of PD over time cannot be observed, unlike when using a specific PD (shown in the interaction between the mixed cluster and time squared). A dichotomous PD variable such as "having PD" or "not having PD" is not like "having" high blood pressure or "not having" high blood pressure, as it depends on the proportion of influential PDs within a given sample. Therefore, using a dichotomous PD variable could result in bias.

Lastly, even using a specific PD (cluster A, B, C, or mixed) may not be enough. While cluster A PDs seemed to be more homogenous, as they shared biological, psychological, and even diagnostic criteria, there was inconsistency among the $\mathrm{PDs}$ in cluster $\mathrm{B}$ and $\mathrm{C}$ in this regard. ${ }^{37-39}$ More importantly, the contribution of each PD to depression was different, even in the same cluster. For example, a borderline PD had a stronger impact on depression than a histrionic PD or antisocial PD in the same cluster (B). An avoidant PD may have contributed more than a dependent PD in cluster C. ${ }^{1,40}$ Therefore, the fact that borderline PDs and histrionic PDs appeared in the same cluster when assessing their effects on depression may have also resulted in bias.

With regard to depression, to test the efficacy of any particular intervention, either medication or some kind of psychotherapy, using a reliable way to establish the presence of a PD should be prioritized. Adding a dimensional personality, as is the case in DSM-5, is one approach which may be used to secure the personality factor. However, personality and depression may be difficult to separate, as found by a recent investigation concerning the interaction between PDs and depression. ${ }^{7}$ An alternative option is for personality and depression to be treated as a single unit (outcome) instead of being separated; for example, borderline PD/depression, obsessive-compulsive PD/ depression, schizoid PD/depression, or mixed PD/depression, and for dimensional personality traits as additional outcome variables. This, however, is a subject for future research.

This study had several limitations that should be mentioned. First, the fact that the PD interviews were administered at the end of the project might have affected their validity and reliability, as some participants were still in a depressive state. Even though there was evidence to show the stability of the patients' personalities, it could not be ascertained whether this was related to the depression, to the $\mathrm{PD}$, or to the interaction between them. Second, the sample size was quite small, and, as a result, it may not have been possible to ascertain any significant difference between those with PDs and those with no PDs.

Third, even though we attempted to identify specific PD clusters for individuals, some PDs related to depression were still not included, such as depressive PD. ${ }^{41}$ The differences in impacts by various PDs emphasize the disadvantage of classifying PDs into only two categories when testing for their effects on depression.

Fourth, the different types of depression, eg, major depressive disorder or dysthymic disorder, were not separately analyzed because the sample size was small, and this might have affected the results because different types of PDs may have different impacts on different types of depression. ${ }^{1}$

Finally, even though the therapist factor was found to be important and should be considered as level 3 in a multilevel model, ${ }^{42,43}$ we could not include it here as the nature of our setting did not allow it. More importantly, it was sometimes difficult to assess the psychotherapy provided as additional 
treatment and in particular any therapeutic alliance issues arising; this is an important factor in psychotherapy. ${ }^{44}$

\section{Conclusion}

PDs had an impact on the course of treatment and treatment outcomes among the depression patients assessed as part of this longitudinal, observational study. PDs played specific roles at different stages; for example, prior to treatment, PD was a predisposing factor, and during treatment, PD interacted with time or with the therapy given, including the therapist. Therefore, to effectively explore their impacts depends on what specific types of PDs are being studied and on how long and how frequently the assessment takes place.

\section{Acknowledgments}

This study was funded by the Faculty of Medicine, Chiang Mai University and partly the National Research Council of Thailand. Data with regard to THAISAD project was supported by the Medical Research Network of the Consortium of Thai Medical Schools and by the Faculty of Medicine, Chiang Mai University.

\section{Disclosure}

The authors report no conflicts of interest in this work.

\section{References}

1. Friborg O, Martinsen EW, Martinussen M, Kaiser S, Overgård KT, Rosenvinge JH. Comorbidity of personality disorders in mood disorders: a meta-analytic review of 122 studies from 1988 to 2010. J Affect Disord. 2014;152-154:1-11.

2. Grilo CM, Sanislow CA, Shea MT, et al. Two-year prospective naturalistic study of remission from major depressive disorder as a function of personality disorder comorbidity. J Consult Clin Psychol. 2005;73(1): 78-85.

3. Grilo CM, Stout RL, Markowitz JC, et al. Personality disorders predict relapse after remission from an episode of major depressive disorder: a 6-year prospective study. J Clin Psychiatry. 2010;71(12): 1629-1635.

4. Mulder RT, Joyce PR, Frampton CM, Luty SE, Sullivan PF. Six months of treatment for depression: outcome and predictors of the course of illness. Am J Psychiatry. 2006;163(1):95-100.

5. Candrian M, Schwartz F, Farabaugh A, Perlis R, Ehlert U, Fava M. Personality disorders and perceived stress in major depressive disorder. Psychiatry Res. 2008;160(2):184-191.

6. Miller JD, Pilkonis PA. Neuroticism and affective instability: the same or different? Am J Psychiatry. 2006;163(5):839-845.

7. Gunderson JG, Stout RL, Shea MT, et al. Interactions of borderline personality disorder and mood disorders over 10 years. J Clin Psychiatry. 2014;75(8):829-834.

8. Devanand D, Turret N, Moody B, et al. Personality disorders in elderly patients with dysthymic disorder. Am J Geriatr Psychiatry. 2000;8(3):188-195

9. Duberstein PR, Pálsson SP, Waern M, Skoog I. Personality and risk for depression in a birth cohort of 70-year-olds followed for 15 years. Psychol Med. 2008;38(5):663-671.
10. Fava M, Farabaugh AH, Sickinger AH, et al. Personality disorders and depression. Psychol Med. 2002;32(6):1049-1057.

11. Gunderson JG, Morey LC, Stout RL, et al. Major depressive disorder and borderline personality disorder revisited: longitudinal interactions. J Clin Psychiatry. 2004;65(8):1049-1056.

12. Skodol AE, Shea MT, Yen S, White CN, Gunderson JG. Personality disorders and mood disorders: perspectives on diagnosis and classification from studies of longitudinal course and familial associations. J Pers Disord. 2010;24(1):83-108.

13. Viinamäki H, Tanskanen A, Koivumaa-Honkanen $\mathrm{H}$, et al. Cluster $\mathrm{C}$ personality disorder and recovery from major depression: 24-month prospective follow-up. J Pers Disord. 2003;17(4):341-350.

14. Kool S, Schoevers R, de Maat S, et al. Efficacy of pharmacotherapy in depressed patients with and without personality disorders: a systematic review and meta-analysis. J Affect Disord. 2005;88(3):269-278.

15. Joyce PR, McKenzie JM, Carter JD, et al. Temperament, character and personality disorders as predictors of response to interpersonal psychotherapy and cognitive-behavioural therapy for depression. $\mathrm{Br} J$ Psychiatry. 2007;190:503-508.

16. Mulder RT. Personality pathology and treatment outcome in major depression: a review. Am J Psychiatry. 2002;159(3):359-371.

17. De Bolle M, De Fruyt F, Quilty LC, Rolland JP, Decuyper M, Bagby RM. Does personality disorder co-morbidity impact treatment outcome for patients with major depression? A multi-level analysis. J Pers Disord. 2011;25(1):1-15.

18. Moradveisi L, Huibers MJ, Renner F, Arasteh M, Arntz A. The influence of comorbid personality disorder on the effects of behavioural activation vs antidepressant medication for major depressive disorder: results from a randomized trial in Iran. Behav Res Ther. 2013;51(8):499-506.

19. Snijders TAB, Bosker RJ. Multilevel Analysis: An Introduction to Basic and Advanced Multilevel Modeling, 2nd edition. London: Sage Publishers; 1999.

20. Wongpakaran T, Wongpakaran N, Pinyopornpanish M, et al. Baseline characteristics of depressive disorders in Thai outpatients: findings from the Thai Study of Affective Disorders. Neuropsychiatr Dis Treat. 2014; 10:217-223.

21. Sheehan D, Lecrubier Y, Sheehan KH, et al. The Mini-International Neuropsychiatric Interview (M.I.N.I.): the development and validation of a structured diagnostic psychiatric interview for DSM-IV and ICD-10. J Clin Psychiatry. 1998;59(Suppl 20):22-33; quiz 34-57.

22. Kittirattanapaiboon $\mathrm{P}$, Khamwongpin M. The Validity of the Mini International Neuropsychiatric Interview (M.I.N.I.)-ThaiVersion. Journal of Mental Health of Thailand. 2005;13(3):126-136.

23. Farabaugh A, Mischoulon D, Yeung A, et al. Predictors of stable personality disorder diagnoses in outpatients with remitted depression. J Nerv Ment Dis. 2002;190(4):248-256.

24. Lotrakul M, Sukanich P, Sukying C. The reliability and validity of Thai version of Hamilton Rating Scale for Depression. J Psychiatr Assoc Thailand. 1996;41(4):235-246.

25. Wongpakaran T, Wongpakaran N. Structured Clinical Interview for DSM-IV ${ }^{\circledR}$ Axis II Personality Disorders (SCID-II) Thai version. Bangkok: IGroup Press Co.Ltd; 2012.

26. Wongpakaran T, Wongpakaran N, Bookkamana P, et al. Interrater reliability of Thai version of the Structured Clinical Interview for DSM-IV Axis II Personality Disorders (T-SCID II). J Med Assoc Thai. 2012; 95(2):264-269.

27. Twisk JW. Applied Multilevel Analysis: A Practical Guide. New York: Cambridge University Press; 2006.

28. Seltman HJ. Experimental Design and Analysis. Pittsburgh: Carnegie Mellon University; 2014. Available from: http://www.stat.cmu. edu/ hseltman/309/Book/Book.pdf. Accessed January 21, 2015.

29. Hox J. Multilevel analysis: Techniques and Applications (Quantative Methodology Series). 2nd ed. New York: Routledge Academic; 2010.

30. Strandholm T, Karlsson L, Kiviruusu O, Pelkonen M, Marttunen M. Treatment characteristics and outcome of depression among depressed adolescent outpatients with and without comorbid Axis II disorders. J Pers Disord. 2014;28(6):853-863. 
31. Agosti V. Predictors of remission from chronic depression: A prospective study in a nationally representative sample. Compr Psychiatry. 2014;55(3):463-467.

32. Farabaugh A, Mischoulon D, Schwartz F, Pender M, Fava M, Alpert J. Dysfunctional attitudes and personality disorder comorbidity during long-term treatment of MDD. Depress Anxiety. 2007;24(6):433-439.

33. Riihimäki K, Vuorilehto M, Isometsä E. Borderline personality disorder among primary care depressive patients: a five-year study. J Affect Disord. 2014;155:303-306.

34. Gunderson JG, Stout RL, McGlashan TH, et al. Ten-year course of borderline personality disorder: psychopathology and function from the Collaborative Longitudinal Personality Disorders study. Arch Gen Psychiatry. 2011;68(8):827-837.

35. Grilo CM, Stout RL, Markowitz JC, et al. Personality disorders predict relapse after remission from an episode of major depressive disorder: a 6-year prospective study. J Clin Psychiatry. 2010;71(12):1629-1635.

36. Yoshimatsu K, Palmer B. Depression in patients with borderline personality disorder. Harv Rev Psychiatry. 2014;22(5):266-273.

37. Esterberg ML, Goulding SM, Walker EF. A personality disorders: schizotypal, schizoid and paranoid personality disorders in childhood and adolescence. J Psychopathol Behav Assess. 2010;32(4):515-528.

38. Cohen AS, Emmerson LC, Mann MC, Forbes CB, Blanchard JJ. Schizotypal, schizoid and paranoid characteristics in the biological parents of social anhedonics. Psychiatry Res. 2010;178(1):79-83.
39. First MB, Gibbon M, Spitzer RL, Williams JBW, Benjamin LS eds. Structured Clinical Interview for DSM-IV Axis II Personality Disorder (SCID-II). Arlington: American Psychiatric Publishing; 1997.

40. Zimmerman M, Chelminski I, Young D, Dalrymple K, Martinez J, Morgan TA. Which DSM-IV personality disorders are most strongly associated with indices of psychosocial morbidity in psychiatric outpatients? Compr Psychiatry. 2012;53(7):940-945.

41. Renner F, Bamelis LL, Huibers MJ, Speckens A, Arntz A. The impact of comorbid depression on recovery from personality disorders and improvements in psychosocial functioning: Results from a randomized controlled trial. Behav Res Ther. 2014;63:55-62.

42. Kuyken W, Tsivrikos D. Therapist competence, comorbidity and cognitive-behavioral therapy for depression. Psychother Psychosom. 2009;78(1):42-48.

43. Elkin I, Falconnier L, Smith Y, et al. Therapist responsiveness and patient engagement in therapy. Psychother Res. 2014;24(1):52-66.

44. Krupnick JL, Sotsky SM, Simmens S, et al. The role of the therapeutic alliance in psychotherapy and pharmacotherapy outcome: findings in the National Institute of Mental Health Treatment of Depression Collaborative Research Program. J Consult Clin Psychol. 1996;64(3): $532-539$.
Neuropsychiatric Disease and Treatment

\section{Publish your work in this journal}

Neuropsychiatric Disease and Treatment is an international, peerreviewed journal of clinical therapeutics and pharmacology focusing on concise rapid reporting of clinical or pre-clinical studies on a range of neuropsychiatric and neurological disorders. This journal is indexed on PubMed Central, the 'PsycINFO' database and CAS,

\section{Dovepress}

and is the official journal of The International Neuropsychiatric Association (INA). The manuscript management system is completely online and includes a very quick and fair peer-review system, which is all easy to use. Visit http://www.dovepress.com/testimonials.php to read real quotes from published authors. 